\title{
Blast induced brain injuries - a grand challenge in TBI research
}

\section{Mårten Risling*}

Department of Neuroscience, Karolinska Institutet, Stockholm, Sweden

${ }^{*}$ Correspondence: Marten.Risling@ki.se

The US government has initiated the largest coordinated research programs ever in neurotrauma. The specific focus is to get insight in mechanisms and to provide better treatment for blast induced traumatic brain injuries (BINT, Blast Induced Neuro Trauma) (Ling et al., 2009). The background should probably be well known for anyone working in the field of traumatic brain injuries (TBI). The asymmetric warfare in the recent military conflicts in Iraq and Afghanistan has resulted in numerous attacks with Improvised Explosive Devices (IED) and large losses in terms of deaths and wounded soldiers (Warden, 2006; Terrio et al., 2009). TBI has been identified as major health problem in military personnel returning from service. The injuries range from severe multitrauma to a number of mild TBI that still has to be settled. A large number of research groups with different backgrounds contribute to this effort. In addition, a number of other countries have also ongoing research programs on blast induced brain injuries.

The current research programs are so large and well coordinated so that it is tempting to compare with Apollo Program about 50 years ago. Apart from putting man on the moon that program had several positive spinoff effects in many areas, i.e in electronics. Similar spinoff effects might come in from the current programs. It would be logical that these programs can generate important new knowledge in treatment of mildTBI, diffuse axonal injuries (DAI), the role of inflammation in TBI, neuroprotection, rehabilitation of TBI and acute oedema treatment. Many groups are working with advanced computerized mathematical models of the head to provide understanding of propagation of blast waves. Such models will also be important for the design of better injury prevention in road traffic accidents. More detailed criteria for different types of TBI would also be important tools for improvements of safety in vehicles. We can also expect a lot of data from research on more specific biomarkers for TBI (Wang et al., 2005; Agoston et al., 2009) and evaluation of digital EEG to indentify functional changes. New imaging techniques may get an increasing power to identify DAI and regional vascular perfusion defects after TBI.

To mention a few of the specific problems in BINT:

- Propagation of blast waves is very complex. It could involve both direct propagation through the skull and indirect propagation via blood vessels (Cernak and Noble-Haeusslein, 2010). If the latter mechanism is important, we could expect effects from vascular disturbance. Several lines of evidence seem to point in that direction.

- Is BINT a specific type injury that will require specific and new types of treatment? Or is, for example, the mild TBI from blast exposure more like a classical type of concussion injury (Hoge et al., 2009)?

- Is it possible to identify a reliable borderline between mild BINT and posttraumatic stress syndrome (PTSD)? Many of the symptoms are similar and many patients might suffer from both TBI and PTSD (Jaffee and Meyer, 2009).

- Is BINT an entirely new problem? The shellshock syndrome (Anderson, 2008) that was seen after the enormous artillery battles during World War I had similarities to BINT and post BINT symptoms, but for many years it has been regarded as PTSD rather than physical injuries. The new situation with IED is that the explosive often detonates at short distance and that improved body armour and helmets protect much better against penetration from fragments. Could the new body armour also change the physical parameters of the blast wave, in a similar way that is described as BABT (behind armour blunt trauma) (Drobin et al., 2007).
- Although the epidemiology of BINT has been established in terms of approximate numbers of injured, it is very difficult to assess the injury mechanisms in individual cases. Complex propagation and reflection of the primary supersonic blast wave, effects from acceleration and rotation, effects from impact of fragments, effects from heating, effects from emitted gases and electromagnetic waves. Well-designed experimental models are required as well as data from acceleration probes and pressure sensors that have been mounted into helmets and body armour will increase the knowledge of the critical mechanisms.

Tragic experience from military conflicts has on previous occasions generated valuable medical knowledge. During the Roman Empire the army physicians learned the lesson not to close contaminated wounds and they also developed an early set of ethical rules, which also included treatment of wounded enemies. We could also mention the Crimean war and its impact on nursing and sanitary principles as well as a war between Russia and Sweden, that resulted in the foundation of the Karolinska institute to provide better training for Army surgeons, exactly 200 years ago. During more recent years, the careful examination of TBI patients from the Vietnam War has generated very important general knowledge (Raymont et al., 2008; Koenigs and Grafman, 2009).

Thus, it is a grand challenge to extract all useful information from the current research program on blast induced brain injuries. We can expect to see a number of articles dealing with that problem in this journal.

\section{REFERENCES}

Agoston, D. V., Gyorgy, A., Eidelman, O., and Pollard, H. B. (2009). Proteomic biomarkers for blast neurotrauma: targeting cerebral edema, inflammation, and neuronal death cascades. J. Neurotrauma 26, 901-911. 
Anderson, R. J. (2008). Shell shock: an old injury with new weapons. Mol. Interv. 8, 204-218.

Cernak, I., and Noble-Haeusslein, L. J. (2010). Traumatic brain injury: an overview of pathobiology with emphasis on military populations. J. Cereb. Blood Flow Metab. 2, 255-266.

Drobin, D., Gryth, D., Persson, J. K., Rocksen, D., Arborelius, U. P., Olsson, L. G., Bursell, J., and Kjellstrom, B. T. (2007). Electroencephalogram, circulation, and lung function after high-velocity behind armor blunt trauma. J. Trauma. 63, 405-413.

Hoge, C. W., Goldberg, H. M., and Castro, C. A. (2009). Care of war veterans with mild traumatic brain injury-flawed perspectives. N. Engl. J. Med. 360, 1588-1591.

Jaffee, M. S., and Meyer, K. S. (2009). A brief overview of traumatic brain injury (TBI) and post-traumatic stress disorder (PTSD) within the Department of Defense. Clin. Neuropsychol. 23, 1291-1298.
Koenigs, M., and Grafman, J. (2009). Posttraumatic stress disorder: the role of medial prefrontal cortex and amygdala. Neuroscientist 15, 540-548.

Ling, G., Bandak, F., Armonda, R., Grant, G., and Ecklund, J. (2009). Explosive blast neurotrauma.J. Neurotrauma 26, 815-25.

Raymont, V., Greathouse, A., Reding, K., Lipsky, R., Salazar, A., and Grafman, J. (2008). Demographic, structural and genetic predictors of late cognitive decline after penetrating head injury. Brain 131, 543-558.

Terrio, H., Brenner, L. A., Ivins, B. J., Cho, J. M., Helmick, K., Schwab, K., Scally, K., Bretthauer, R, and Warden, D. (2009). Traumatic brain injury screening: preliminary findings in a US Army Brigade Combat Team. J. Head Trauma Rehabil. 24, 14-23.

Wang, K. K., Ottens, A. K, Liu, M. C., Lewis, S. B, Meegan, C., Oli, M. W., Tortella, F. C., and Hayes, R. L.(2005). Proteomic identification of biomarkers of traumatic brain injury. Expert Rev. Proteomics 2, 603-614.

Warden, D. (2006). Military TBI during the Iraq and Afghanistan wars. J. Head Trauma Rehabil. 21, 398-402.

Received: 29 January 2010; accepted: 03 February 2010; published online: 08 March 2010.

Citation: Risling M (2010) Blast induced brain injuries a grand challenge in TBI research. Front. Neur. 1:1. doi: 10.3389/fneur.2010.00001

This article was submitted to Frontiers in Neurotrauma a specialty of Frontiers in Neurology.

Copyright $\odot 2010$ Risling. This is an open-access article subject to an exclusive license agreement between the authors and the Frontiers Research Foundation, which permits unrestricted use, distribution, and reproduction in any medium, provided the original authors and source are credited. 